Bangladesh J. PI. Breed. Genet, 25(1): 11-16, 2012

\title{
GENETIC DIVERSITY AND PARENTS SELECTION FROM EXOTIC RICE (Oryza sativa L.) GERMPLASM
}

\author{
A. A. Mamun, N. A. Ivy, M. G. Rasul and M. M. Hossain ${ }^{1}$ \\ Department of Genetics and Plant Breeding \\ Bangabandhu Sheikh Mujibur Rahman Agricultural University \\ Gazipur 1706, Bangladesh
}

\begin{abstract}
Genetic divergence among fifty exotic rice genotypes along with two check varieties were estimated using $\mathrm{D}^{2}$ and principal component analysis. The study was undertaken to select suitable donor parents for use in improved breeding program of Bangabandhu Sheikh Mujibur Rahman Agricultural University in 2009. Principal component analysis (PCA) revealed that the first five axes accounted for $58.10 \%$ of the total variation. As per cluster analysis, the genotypes were grouped into seven clusters consisting 11, 16, 7, 11, 1, 2 and 4 genotypes which revealed that there exist considerable diversity among the genotypes. Considering the magnitude of genetic distance, contribution of different characters towards the total divergence and magnitude of cluster means for different characters, the genotypes RG-BU-08-057, 61, 65, 67, 69, 71, 85, $86,88,94,96,98$ and 99 might be selected as a suitable parent for future hybridization program.
\end{abstract}

Key words: Rice (Oryza sativa L.), genetic variability, parents, hybridization.

\section{INTRODUCTION}

Rice (Oryza sativa L.) is the second largest cereal in the world. With the increasing population pressure, the demand of cereal is increasing day by day. Bangladesh agricultural economy predominantly based on rice production. Rice occupies about $75 \%$ of the total cropped area and constitutes $94 \%$ of cereals production (Anonymous, 1999). Although Bangladesh is now on the verge of attaining selfsufficiency in cereal production, there is still a major gap between the production and demand. Two-third of Bangladesh populations is engaged in livelihood activities related to rice. (http//.asiarice.org./asiarice/demosite/sections/chapters/ Bangladesh/BRF). Production potentiality of rice does not only depend on cultural practices and management, but also on the suitability of rice varieties. Development of potential rice varieties depends on existing germplasm collected and conserved by genetic resources centers ( $\mathrm{Ng}$ et al., 1988). The progress of breeding is conditioned by the magnitude and nature of inter-relationship among the characters and variation of different of characteristics. Knowledge about genetic control of the characters is essential in formulating an efficient breeding scheme as it provides not only a basis for selection but also some valuable indication relating selection of parents to be hybridized. Exotic species present potential donor sources for complex traits such as yield and would help to realize the dream of sustained food security. However, the utilization of these rice

${ }^{1}$ Department of Horticulture, Bangabandhu Sheik Mujibur Rahman Agricultural University, Gazipur 1706, Bangladesh. 
genetic resources had been limited to only adaptable genotypes (Caldo et al., 1996). Genetic diversity is a useful tool in quantifying the degree of divergence in a biological population at genotypic level and to assess relative contribution of different components to the total divergence both at intra and inter-cluster levels (Jatasara and Paroda, 1978). Cluster analysis is also carried out to detect divergent parents for hybridization purposes and to attain meaningful group constellations of a collection of genotypes. Considering the availability of genetic variability, its scope of yield improvement and export potential, the present investigation was undertaken to search suitable diverse germplasm as suitable donor parents for the utilization in future breeding program.

\section{MATERIALS AND METHODS}

A total of fifty exotic rice genotypes and two varieties, collected from Department of Genetics and Plant Breeding of Bangabandhu Sheikh Mujibur Rahman Agricultural University (BSMRAU), Salna, Gazipur namely: RG-BU-08-051 to RG-BU08-100, BRRI dhan28 and BRRI dhan29, were grown at the experimental farm of BSMRAU, Gazipur following randomized block design with three replications in 2009. The field was divided into three blocks, the blocks were subdivided into 52 plots where genotypes were randomly assigned. The unit plot size was $12.5 \mathrm{~m} \times 2.5 \mathrm{~m}$. Each plot had two lines. Row to row and plant to plant distances were $25 \mathrm{~cm}$ and $20 \mathrm{~cm}$ respectively. Standard agronomic practices were followed to raise a good crop. Observations were recorded on days to first flowering (DFF), days to $50 \%$ flowering (50\%DF), days to harvesting $(\mathrm{DH})$, anther length $(\mathrm{AL})$, anther breadth $(\mathrm{AB})$, stigma length (SL), stigma breadth (SB), pollen sterility (PS), pollen fertility (PF), spikelet sterility (SS), out crossing rate (OCR), filled grains per panicle (FGP), unfilled grains per panicle (UGP), grain length (GL), grain breadth (GB) and grain yield per hill (GYH). Data were subjected to both univariate and multivariate analysis. Under multivariate analysis Principal Component Analysis (PCO), Principal Coordinate Analysis (PCA), Cluster Analysis (CA) and Canonical Vector Analysis were done by using GENSTAT 5.5 program.

\section{RESULTS AND DISCUSSION}

Analysis of variance showed significant variations among the tested genotypes for all the characters studied indicating a wide range of genotypic variation among the genotypes. Estimated eigen values of principal component indicated that the first five axes accounted for $58.10 \%$ of the total variation while the former two accounted for $27.07 \%$. These results are in agreement with the findings of Ogunbayo et al. (2005). On the basis of principal axes I and II, a two dimension chart $\left(Z_{1}-Z_{2}\right)$ of the genotypes are presented in Fig. 1. As per the scattered diagram the genotypes were apparently distributed into seven clusters.

Non-hierarchical clustering using co-variance matrix among the genotypes grouped the rice genotypes into seven clusters. Singh et al. (1987) and Rao et al. (1981) reported ten clusters, Anandakummar and Subramanian (1989), and Biswas and Sasmal (1990) reported six clusters and Ratho (1984) reported five clusters in rice genotypes. The clustering pattern is determined by the principal component analysis (Table 1) which represent the composition of different clusters with the genotypes. The distribution pattern of the genotypes indicated that the maximum genotypes (16) were included in cluster II followed by cluster I \& IV (11), cluster III (7), cluster VII (4), cluster VI (2) and cluster V (1). Genotypes in seven clusters were ranged from 1 to 16 . The distribution 
of genotypes into seven clusters revealed that there exists considerable diversity among the genotypes.

Table 1. Distribution of 50 exotic rice genotypes with two check varieties in seven clusters

\begin{tabular}{c|cll}
\hline Cluster & Members & \multicolumn{1}{c}{ Name of Genotypes } \\
\hline I & 11 & RG-BU-08-055, 57, 65, 67, 71, 74, 81, 84, 85, 86 \\
II & 16 & RG-BU-08-053, 54, 58, 60, 61, 63, 64, 69, 70, 72, 78, 89, 91, 92, 96, 97 \\
III & 7 & RG-BU-08-068, 76, 79, 80, 82, 93, 95 \\
IV & 11 & $\begin{array}{l}\text { RG-BU-08-051, 52, 56, 62, 77, 83, 90, 94, 100, BRRI dhan28, BRRI } \\
\text { dhan29 }\end{array}$ \\
V & 1 & RG-BU-08-099 \\
VI & 2 & RG-BU-08-088, 98 \\
VII & 4 & RG-BU-08-059, 73, 75, 87 \\
\hline
\end{tabular}

Intra-cluster distances were estimated using the inter genotypic distance (Table 2) following Singh and Chaudhury (1977). The highest intra-cluster distance was recorded in cluster VII (2.08) containing four genotypes followed by cluster I (1.65) with eleven genotypes. The lowest intra-cluster distance was observed in cluster V (0) having the lowest (1) number of genotype and the cluster II showed the second lowest intra cluster distance (0.13) having the highest (16) number of genotypes. Such results indicated that the genotypes of cluster VII were more heterogeneous as compared to those included in cluster II.

The highest inter-cluster distance was observed between cluster $\mathrm{V}$ and VI (36.37) followed by clusters V and VII (36.08) (Table 2). The lowest inter-cluster distance was observed between cluster IV and VI (0.56) followed by cluster II and IV (0.74). The maximum value of inter cluster distance indicated that the genotypes belonging to cluster $\mathrm{V}$ was far diverged from those of cluster VI. The minimum inter cluster divergence was observed between cluster IV and VI (0.56) indicating that the genotypes of these clusters were genetically closed. However, genotypes within the other pair of clusters indicated that they were less diverged. The inter cluster distances in all the clusters were higher than the intra cluster distances suggesting wider genetic diversity among the genotype of different groups. The results were in agreement with Rahman et al. (1997) and Singh and Chaudhury (1985).

Table 2. Average intra (Diagonal) and intercluster distances $\left(\mathrm{D}^{2}\right)$ of 50 exotic rice genotypes with 2 check varieties on the basis of sixteen morphological characters

\begin{tabular}{|c|c|c|c|c|c|c|c|}
\hline & I & II & III & IV & V & VI & VII \\
\hline I & 1.65 & & & & & & \\
\hline II & 10.62 & 0.13 & & & & & \\
\hline III & 4.34 & 6.44 & 1.52 & & & & \\
\hline IV & 11.34 & 0.74 & 7.12 & 0.32 & & & \\
\hline $\mathrm{V}$ & 34.05 & 35.53 & 35.14 & 35.92 & 0 & & \\
\hline VI & 11.16 & 0.88 & 6.90 & 0.56 & 36.37 & 1.08 & \\
\hline VII & 8.11 & 2.88 & 3.78 & 3.48 & 36.08 & 3.17 & 2.08 \\
\hline
\end{tabular}

Higher inter and intra-cluster distances indicated higher genetic variability among genotypes between and within clusters, respectively. The minimum inter and intra-cluster distance indicated closeness among the genotypes of two clusters and within 
the cluster also. These relationships, in respect of genetic distance, were also reflected in the scatter diagram (Fig. 1). Genotypes belonging to the distant clusters could be used in hybridization program for obtaining a wide spectrum of variation among the segregants (Mokate et al., 1998). Crossing might be carried out between genotypes belonging to different clusters having genetic distances $\left(\mathrm{D}^{2}\right)$ greater than 12.5 (Wei et al., 1994). Thus parents selected from the distant clusters V, VI and VII may manifest the highest level of heterotic response in crosses.

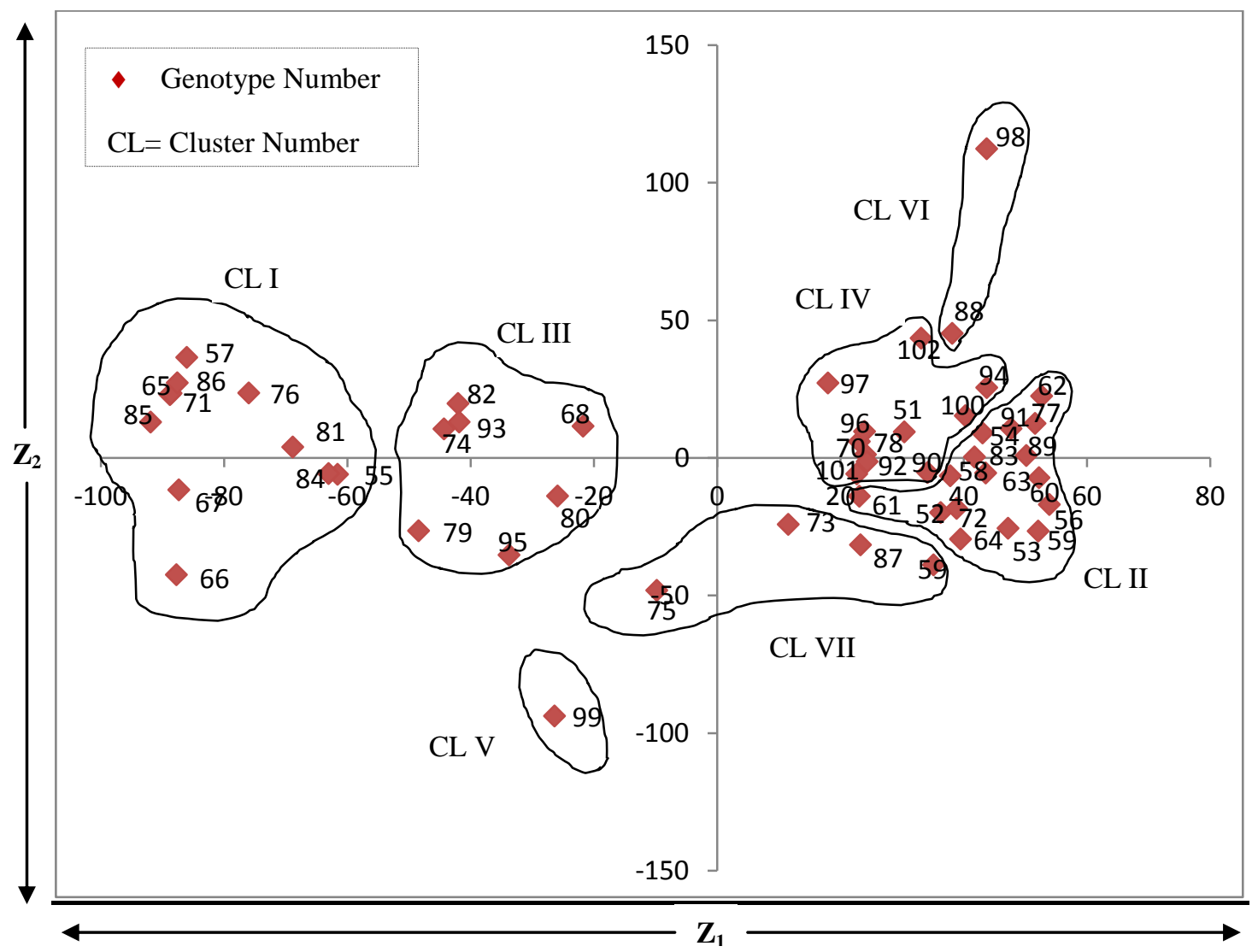

Fig. 1: Relative position of 50 exotic rice genotypes with 2 check varieties in $Z_{1}-Z_{2}$ graph based on the morphological characters superimposed with clustering.

Results of 10 higher and 10 lower inter genotypic estimated from distant matrix of Principal Coordinate Analysis are shown in Table 3. The highest inter genotypic distance (6.448) was observed between RG-BU-08-085 and RG-BU-08-069 followed by the distance 6.444 observed between RG-BU-08-085 and RG-BU-08-062. Genotypes RG-BU-08-085 and RG-BU-08-069, a high level of pollen fertility with moderate seed length and seed breadth, may be selected as parent. Genotypes RG-BU-08-086, 57, 65 etc. may be selected as parents for hybridization since Chauhan and Singh (1982) reported maximum heterosis observed in those crosses, which were involved moderately diverged parents. Ying et al. (1991) also reported the heterobeltiosis from the cross between intermediate distant classes. Buu and Tuan (1989) and Joshi and Dhawan (1966) reported that genetic diversity is very much important factor for any hybridization program aiming at genetic improvement of yield especially in self-pollinated crops like rice. Bhatt (1970) inferred that Mahalanobis's $D^{2}$ statistic is a powerful tool for choosing diverse parents for hybridization. 
Table 3. Ten higher and ten lower inter genotypic distance among the 50 exotic rice genotypes with 2 check varieties from distance matrix in $\mathrm{PCO}$

\begin{tabular}{lccc}
\hline \multicolumn{2}{c|}{ Sl. No. } & Genotypic combination & Distances \\
\hline \multicolumn{2}{c}{ A. 10 higher inter genotypic distance } & \\
\hline 01 & RG-BU-08-085 - RG-BU-08-069 & 6.448 \\
02 & RG-BU-08-085 - RG-BU-08-062 & 6.444 \\
03 & RG-BU-08-084 - RG-BU-08-056 & 6.310 \\
04 & RG-BU-08-085 - RG-BU-08-077 & 6.222 \\
05 & RG-BU-08-086 - RG-BU-08-069 & 6.004 \\
06 & RG-BU-08-086 - RG-BU-08-062 & 5.968 \\
07 & RG-BU-08-069 - RG-BU-08-057 & 5.931 \\
08 & RG-BU-08-086 - RG-BU-08-060 & 5.915 \\
09 & RG-BU-08-086 - RG-BU-08-056 & 5.865 \\
10 & RG-BU-08-069 - RG-BU-08-065 & 5.852 \\
\hline \multicolumn{3}{c}{ B. 10 lower inter genotypic distance } & \\
\hline 01 & RG-BU-08-071 - RG-BU-08-057 & 0.380 \\
02 & RG-BU-08-071 - RG-BU-08-065 & 0.387 \\
03 & RG-BU-08-086- RG-BU-08-065 & 0.473 \\
04 & RG-BU-08-084- RG-BU-08-055 & 0.502 \\
05 & RG-BU-08-063- RG-BU-08-054 & 0.524 \\
06 & RG-BU-08-065 - RG-BU-08-057 & 0.588 \\
07 & RG-BU-08-078- RG-BU-08-070 & 0.597 \\
08 & RG-BU-08-091 - RG-BU-08-063 & 0.604 \\
09 & RG-BU-08-092 - RG-BU-08-070 & 0.610 \\
10 & RG-BU-08-074 - RG-BU-08-068 & 0.613 \\
\hline
\end{tabular}

Considering the magnitude of genetic distance, contribution of different characters towards the total divergence and magnitude of cluster means for different characters the genotypes RG-BU-08-057, 61, 65, 67, 69, 71, 85, 86, 88, 94, 96, 98, \& 99 might be selected as parents for efficient hybridization program.

\section{REFERENCES}

Anandakumar, C. R. and M. Subramarnian. 1989. Genetic divergence in upland rice. International Rice Research Newsletter. 14(4): 6-7.

Anonymous. 1999. Time and requirement of topdressing of urea according to season and variety. Adhunik Dhaner Chash, Bangladesh Rice Res. Inst., p. 28.

Bhatt, G. M. 1970. Multivariate analysis approach to selection of parents of hybridization aiming at yield improvement in self-pollinated crops. Aust. J. Agric. Res. 21: 1-7.

Biswas, P. K. and B. Sasmal. 1990. An estimate of genetic divergence using both the root and shoot characters among parents and $\mathrm{F}_{1}$ hybrids of rice. Environment and Ecology. 8(1B): 346-348.

Buu, B. C. and T. M. Tuan. 1989. Genetic diversity in rice (Oryza sativa L.). Int. Rice Res. Newslett. 14: 6.

Caldo, R. A, L. S. Sebastian, J. E. Hernandez. 1996. Morphology-Based Genetic Diversity Analysis of Ancestral Lines of Rice in Philippine Rice Cultivars. Philippines Journal of Crop Sciences. 21(3): 86-92. 
Chauhan, V. S. and B. B. Singh. 1982. Heterosis and genetic variability in relation to genetic divergence in soybean. Indian J. Genet. Pl. Breed. 42(2): 324-328.

Jatasara, D. S. and R. S. Paroda. 1978. Genetic divergence in Wheat under different environmental conditions. Cereal Res. Comm., 6:307-317.

Joshi, A. B. and N. L., Dhawan. 1966. Genetic improvement of yield with special reference to self-fertilizing crops. Indian J. Genet. Pl. Breed. 26A: 101-113.

Mokate, A. S., S. S. Mehetre, V. W. Bendale and S. P. Birari. 1998. Genetic divergence in rice. Advances in Plant Sci. 11(2): 189-192.

Ng, N. Q., T. T. Chang, D. A. Vaughan, V. C. Zuno-Alto. 1988. Africa Rice Diversity: Conservation and Prospect for Crop Improvement. Crop Genetic Resources Africa. II: 213-227.

Ogunbayo, S., D. K. Ojo, R. G. Guei, O. O. Oyelakin and K. A. Sanni. 2005. Phylogenetic diversity and relationships among 40 rice accessions using morphological and RAPDs techniques. African Journal of Biotechnology. 4(11): 1234-1244.

Rahman, M., B. Acharya, S. N. Shukla and K. Pande. 1997. Genetic divergence in lowland rice (Oryza sativa L.) germplasm. 34(3): 209-212.

Rao, A. V., A. S. R., Prashad, T. Sai Krishna, D. V. Seshu and T. E. Srinivasan. 1981.Genetic divergence among some brown planthopper resistant rice varieties. Indian J. Genet. Pl. Breed. 41(2): 179-185.

Ratho, S. N. 1984. Genetic divergence in scanted varieties of rice. Indian J. Agril. Sci. 54(9): 699-701.

Singh, R. K. and B. D. Chaudhury. 1985. Biometrical Methods in Quantitative Genetic Analysis. Revised Edn.; Kalyani Publisher. p318.

Singh, S. K. and B. D. Chaudhury. 1977. Biometrical methods in quantitative genetic analysis. Kalyani publishers, New Delhi. pp. 215-238.

Singh, S. K., R. S. Singh, D. M. Maurya, O. P. Verma. 1987. Genetic divergence among low land rice cultivars. Indian J. Genet. Pl. Breed. 47(1): 11-14.

Wei, W. X., H. Zhang, F. U. Lu and S. L. Wei. 1994. Principal component analysis and genetic distance estimation and their application in sesame breeding programme. Acta Agriculturse Boreali Sinica. 9(3): 29-33.

Ying, P. J., S. S. Virmani and A. W. Julfiquar. 1991. Relationship between heterosis and genetic divergence in rice (Oryza sativa L.). 28: 129-133. 